\title{
A comparison of the Psychiatric Bulletin in two time periods: 1988-1992 and 2002-2006
}

\author{
AIMS AND METHOD \\ We sought to gain an impression of \\ how the Psychiatric Bulletin has \\ changed over time. We took a \\ 'snapshot' of the journal in two time \\ periods, comparing characteristics \\ of articles published early in its \\ development (1988-1992) with
}
those published more recently in its current format (2002-2006).
RESULTS
The Bulletin has become more scien- tific, with the proportion of articles categorised as 'original' increasing from $31 \%(217 / 700)$ in the early period to $47 \%(263 / 565)$ in the later

\begin{abstract}
period. There is less emphasis on history of psychiatry and the arts.

CLINICAL IMPLICATIONS

Changes in the Bulletin are in line with psychiatry and medicine in general, placing more emphasis and value on research with systematic methodology.
\end{abstract}

The Psychiatric Bulletin was derived from a 'miscellany' section in the Journal of Mental Science (the forerunner of the British Journal of Psychiatry) in the 1860s. In 1936 it became a separate news supplement. With the formation of the Royal College of Psychiatrists in 1971 it was named News and Notes, and became a forum for comment and opinion on issues of interest in psychiatry. As the number and variety of articles increased, it became a fully fledged journal in its own right. ${ }^{1}$ In October 1988 it was given its present title of the Psychiatric Bulletin.

The Bulletin is currently circulated to over 12000 subscribers, mainly in the UK (D. Jago, personal communication, 2007). It is valued by consultants and trainees alike. ${ }^{2}$ It focuses on topical issues and matters relevant to everyday clinical psychiatric practice. With this focus and its history it can be considered a source of information about the changing nature of psychiatric practice in Britain.

We sought to gain an impression of how the journal has changed over time. We decided to take a 'snapshot' of the Bulletin in two time periods, comparing the characteristics of articles published early in the journal's development (1988-1992) with those published more recently in its current format (20022006). As psychiatric subspecialties have become more established with time, we also sought to identify whether the proportion of subspecialty articles published in the Bulletin increased in line with this. We also wanted to gain an overall impression of any changes and continuity in issues facing psychiatrists between these two periods.

\section{Method}

Categories were developed for article type and article content.

\section{Article type}

The format of the journal in the earlier period (19881992) was very different from that of the later period
(2002-2006), so only article types represented in both periods were included. This allowed comparison of like with like but meant some articles were excluded.

Articles in both periods were categorised by type into 'original' or 'commentary'. Articles fell into the first category if they presented original data collected in a systematic fashion, which included some clearly delineated methodology. ${ }^{3}$ Included in the 'commentary' group were articles that were regular features in the later format under the headings of 'Opinion and Debate', 'Special Articles' and 'Education and Training'. In the earlier period, only commentary articles consistent with those in the later period were studied. There were no editorials in the earlier period and so editorials were not categorised.

\section{Article content}

The content of articles in both periods was categorised according to the current Royal College of Psychiatrists faculties: Academic, Addictions, Child and Adolescent Psychiatry, Forensic Psychiatry, General and Community Psychiatry, Liaison Psychiatry, Psychiatry of Learning Disability, Psychiatry of Old Age, Psychotherapy, and Rehabilitation and Social Psychiatry. If the content reflected two faculties equally, the article was categorised as half of each faculty (e.g. an article on child and adolescent forensic psychiatry would be classified as half Child and Adolescent and half Forensic). If the article was relevant to three or more faculties it was categorised as 'generic'. An additional category ('other') was developed for articles that could not be categorised either into a faculty or as 'generic'. This 'other' category included international articles, Education and Training, History of Psychiatry, the Arts and Psychiatry, Mental Health Law, Informatics, Transcultural Psychiatry, Neuropsychiatry, Eating Disorders, Perinatal Psychiatry and Miscellaneous.

We used our background as practising specialist registrars in psychiatry to develop the categorisation system. We jointly rated articles in the 1988 and 2002 issues of the Bulletin, refining the categories. Each author then individually categorised all the remaining articles in both periods. The overall agreement rate between us (based on categorisation of article content for articles in 
1989 and 2003) was 89\%. Categorisation of articles was then checked together, with any areas of disagreement or uncertainty being discussed until a consensus was reached.

Results were analysed quantitatively using descriptive statistics. Themes in the two time periods were also examined qualitatively.

\section{Results}

Overall, 700 articles were categorised in the 1988-1992 period and 565 articles in the 2002-2006 period. Fewer articles were published in the later period and hence fewer articles were categorised in that period compared with the earlier period. Table 1 shows the total number of articles in the two periods, categorised by faculty.

The faculty most frequently represented in both periods was General and Community Psychiary. Most faculties were represented in similar proportions of the total number of articles in each period. The proportions of Psychiatry of Learning Disability, Psychotherapy, and Rehabilitation and Social Psychiatry articles were smaller in the later period. The proportions of Addictions, Forensic Psychiatry and Psychiatry of Old Age articles were greater in the later period. In both periods a large proportion of articles were classified as 'generic' or as 'other'. Together these made up over half the articles, perhaps reflecting the need to maintain relevance and to be inclusive of all psychiatrists. Table 2 shows the top ten subcategories of articles classified as 'other.'

The proportion of articles relating to History of Psychiatry and the Arts and Psychiatry decreased from the early to the later period. This is perhaps in keeping with editorial policy changes in response to a survey of readership opinion, which showed readers wanted scientific papers of practical relevance to service and clinical matters. ${ }^{4}$ In line with this, the proportion of articles categorised as 'original' rose from $31 \%(217 / 700)$ in $1988-1992$ to $47 \%(263 / 565)$ in 2002-2006. Table 3 shows 'original' articles categorised by faculty. The faculty

Table 1. Comparison of Psychiatric Bulletin articles in the two periods, categorised by faculty

\begin{tabular}{|lcr} 
& $1988-1992$ & $2002-2006$ \\
& $n(\%)$ & $n(\%)$ \\
\hline Faculty & & \\
Academic & $3.5(0.5)$ & $9.5(1.7)$ \\
Addictions & $5(0.7)$ & $22(3.9)$ \\
Child \& Adolescent & $39.5(5.6)$ & $33.5(5.9)$ \\
Forensic & $23(3.3)$ & $26.5(4.7)$ \\
General \& Community & $136.5(19.5)$ & $96(17.0)$ \\
Liaison & $10(1.4)$ & $8.5(1.5)$ \\
Learning Disability & $30.5(4.4)$ & $13(2.3)$ \\
Old Age & $26(3.7)$ & $30.5(5.4)$ \\
Psychotherapy & $32(4.6)$ & $14(2.5)$ \\
Rehabilitation \& Social & $16.5(2.4)$ & $4(0.7)$ \\
Generic & $96(13.7)$ & $139(24.6)$ \\
Other & $281.5(40.2)$ & $168.5(29.8)$ \\
Total & $700(100)$ & $565(100)$ \\
\hline
\end{tabular}

Table 2. The top ten subcategories of 'other' articles in the two

periods

\begin{tabular}{|lcc} 
& $\begin{array}{c}1988-1992 \\
n(\%)^{1}\end{array}$ & $\begin{array}{c}2002-2006 \\
n(\%)\end{array}$ \\
\hline Education \& Training & $89.5(12.8)$ & $80(14.2)$ \\
International & $70(10.0)$ & $33.5(5.9)$ \\
History of Psychiatry & $39(5.6)$ & $3(0.5)$ \\
Arts and Psychiatry & $29(4.1)$ & $4(0.7)$ \\
Mental Health Law & $18.5(2.6)$ & $12(2.1)$ \\
Informatics & $14(2.0)$ & $9.5(1.7)$ \\
Transcultural & $11(1.6)$ & $5.5(1.0)$ \\
Neuropsychiatry & $2.5(0.4)$ & $3(0.5)$ \\
Eating Disorders & $2.0(0.3)$ & $3(0.5)$ \\
Perinatal & $1.5(0.2)$ & $2.5(0.4)$ \\
Miscellaneous & $4.5(0.6)$ & $12.5(2.2)$ \\
Total other & $281.5(40.2)$ & $168.5(29.8)$ \\
\hline
\end{tabular}

1. Percentage of total articles

most frequently represented among the original articles in both periods was the General and Community Psychiatry faculty, and in both periods this faculty was more represented as a proportion of original articles than as a porpotion of all articles.

In the 1988-1992 period a consistent format had not been established and so the headings under which articles were published varied widely between issues. A major theme was the closure of long-stay hospitals and the early development of community services. Experiences of psychiatry from all over the globe were prominent. Interestingly, articles on the Arts and Psychiatry and the History of Psychiatry were regular features. Our impression was that the earlier period often included humorous prose.

An established structure and format was used in the period 2002-2006. The Bulletin appeared to be a more scientific journal at this time. There were fewer dominant themes across the period. However, College initiatives or government policy were addressed in themed issues (e.g. stigma, partners in care and acute in-patient care). Among the original papers, audits were prominent. Articles on psychiatry and the arts or media were represented, but not regularly.

\section{Discussion}

There are limitations in our attempt to look at how the Psychiatric Bulletin has changed. The actual categorisation process and the matching and exclusion of certain headings will have affected the results. Some articles were difficult to categorise: for example, it was hard to differentiate articles on General and Community Psychiatry from Rehabilitation and Social Psychiatry in the earlier period. However, the overall level of agreement between us was $89 \%$. Articles reflecting two faculties equally were categorised as half of each faculty and this could have resulted in lower totals for certain faculties. We did not have access to submission $v$. rejection rates for articles from different faculties, and there are now 
Table 3. Original articles categorised by faculty in the two periods

\begin{tabular}{|lcc} 
& $1988-1992$ & $2002-2006$ \\
& $n(\%)$ & $n(\%)$ \\
\hline Faculty & & \\
Academic & $0(0)$ & $0.5(0.2)$ \\
Addictions & $1.5(0.7)$ & $17.5(6.7)$ \\
Child \& Adolescent & $12.5(5.8)$ & $16.5(6.3)$ \\
Forensic & $7(3.2)$ & $16(6.1)$ \\
General \& Community & $89.5(41.2)$ & $70(26.6)$ \\
Liaison & $5(2.3)$ & $7.5(2.9)$ \\
Learning Disability & $14.5(6.7)$ & $10(3.8)$ \\
Old Age & $12.5(5.8)$ & $21(8.0)$ \\
Psychotherapy & $2.5(1.2)$ & $8(3.0)$ \\
Rehabilitation \& Social & $7(3.2)$ & $2.5(1.0)$ \\
Generic & $34(15.7)$ & $52(19.8)$ \\
Other (subcategories) & & \\
Education and Training & $17.5(8.1)$ & $19.5(7.4)$ \\
International & $5.5(2.5)$ & $8(3.0)$ \\
Remaining other & $8(3.7)$ & $14(5.3)$ \\
Total & $217(100)$ & $263(100)$ \\
\hline
\end{tabular}

more faculty newsletters and specialist journals that psychiatrists can contribute to instead.

In conclusion, the Psychiatric Bulletin has become more scientific over the past 15 years, with an increase in the proportion of original articles being published. There is less emphasis on history of psychiatry and the arts. This is in line with psychiatry and medicine in general placing more emphasis and value on research with systematic methodology and with editorial policy changes to improve quality. One can also speculate that the

increased focus on evidence-based medicine may be contributing. Some aspects of the Bulletin's earlier diversity have been lost as it has become more scientific. Despite this, in our view the journal has successfully preserved its distinctive personality and breadth of subject matter. ${ }^{5}$

\section{Acknowledgements}

We thank Dr Sanju George for his advice, Mr Dave Jago for information provided and DrThomas Bewley for his comments on the manuscript.

\section{Declaration of interest}

None.

\section{References}

1 Bewley T. Madness to Mental Illness: A History of the Royal College of Psychiatrists. Royal College of Psychiatrists, 2008.

2 Kendell RE, Duffett R. The College: an analysis of members' views. Psychiatr Bull 1999; 23: 11-5.

3 Pincus $\mathrm{HA}$, Henderson $B$, Blackwood D, Dial T. Trends in research in two general psychiatric

journals in 1969-1990: research on research. Am J Psychiatry 1993; 150: $135-42$.

4 Fahy T. Psychiatric Bulletin readership survey. Psychiatr Bull 1993; 17: 473-6.

5 Fahy T. Future of the Psychiatric Bulletin. Psychiatr Bull 1998; 22 401.

*Dalia Hanna Specialist Registrar in Old Age Psychiatry, 2nd Floor, Burdett House, Mile End Hospital, 275 Bancroft Road, London E1 4DG, email: daliahnn@yahoo.co.uk, Rosemary Smyth Specialist Registrar in General Adult Psychiatry, City and Hackney Centre for Mental Health, London 